\title{
Non-Specialization of Criminal Careers among Intimate Partner Violence Offenders
}

\author{
N. Zoe Hilton, Ph.D. \\ University of Toronto and Waypoint Research Institute \\ Angela Wyatt Eke, Ph.D. \\ Ontario Provincial Police
}

Version Post-print/accepted manuscript

Citation Hilton, N. Z. \& Eke, A. W. (2016). Nonspecialization of criminal

(published version) careers among intimate partner violence offenders. Criminal Justice and Behavior, 43, 1347-1363. doi: 10.1177/0093854816637886

How to cite TSpace items

\begin{abstract}
Always cite the published version, so the author(s) will receive recognition through services that track citation counts, e.g. Scopus. If you need to cite the page number of the author manuscript from TSpace because you cannot access the published version, then cite the TSpace version in addition to the published version using the permanent URI (handle) found on the record page.
\end{abstract}

This article was made openly accessible by $U$ of $T$ Faculty. Please tell us how this access benefits you. Your story matters. 
Non-Specialization of Criminal Careers among Intimate Partner Violence Offenders

\author{
N. Zoe Hilton, Ph.D.
}

University of Toronto and Waypoint Research Institute

Angela Wyatt Eke, Ph.D.

Ontario Provincial Police

Hilton, N. Z. \& Eke, A. W. (2016). Nonspecialization of criminal careers among intimate partner violence offenders. Criminal Justice and Behavior, 43, 1347-1363. doi: 10.1177/0093854816637886

\title{
Author Note
}

N. Zoe Hilton, Department of Psychiatry, University of Toronto, and Waypoint Research Institute, Penetanguishene, Ontario, Canada; Angela Wyatt Eke, Ph.D., Behavioural Sciences and Analysis Section, Ontario Provincial Police, Orillia, Ontario, Canada.

We would like to thank Amilynn Sharpe, Carol Lang, Kara Brooks, Leslie Jean, Nicole Lewis, Ruth Houghton, Sonja Dey, and Desiree Robitaille for research and administrative assistance, and Glenn Sheil and Karen Arney for their helpful comments on the manuscript as well as our deeply missed colleague and friend Marnie Rice who also provided helpful comments.

Correspondence concerning this article should be sent to N. Zoe Hilton, Ph.D., Waypoint Research Institute, Penetanguishene, 500 Church Street, Penetanguishene, ON, L9M 1G3 Canada. Contact: zhilton@waypointcentre.ca; zoe.hilton@utoronto.ca 


\begin{abstract}
Many men arrested for intimate partner violence (IPV) commit other types of criminal offenses as well. We examined IPV offenders' general offending in more detail than previous studies, and tested the ability of criminal career trajectory and an IPV-specific risk assessment (the Ontario Domestic Assault Risk Assessment; ODARA) to predict post-index recidivism. We retrieved police reports and criminal records of 93 men shortly after an IPV index assault and again 7.5 years later. Most (71\%) had pre-index criminal charges, and most (62\%) had postindex criminal recidivism although fewer (24\%) committed post-index IPV. Pre-index criminal career (defined as none, non-violent, violent, IPV) did not predict post-index IPV whereas the ODARA predicted post-index IPV, AUC $=.67$, as well as other offenses with a moderate or large effect size, including stalking $(\mathrm{AUC}=.78)$, sexual assault $(\mathrm{AUC}=.67)$, and nonviolent offenses $(A U C=.74)$. In line with prior research findings, we conclude that many men arrested for IPV do not specialize in their criminal careers and that risk assessment in these cases should include risk of both IPV and other offenses; furthermore, an existing IPV risk assessment tool, the ODARA, holds promise for assessing general risk of recidivism among IPV offenders. Key Words: intimate partner violence (IPV), domestic violence, criminal careers, specialization, prediction
\end{abstract}


Non-Specialization of Criminal Careers among Intimate Partner Violence Offenders Studies of criminal career patterns indicate that many intimate partner violence (IPV) offenders - those who assault their spouse or dating partner - do not specialize in domestic offending (e.g., Buzawa \& Hirschel, 2008; Klein \& Tobin, 2008; Piquero, Brame, Fagan, \& Moffitt, 2006). The most serious and persistent batterers appear most likely to engage in other types of violent and criminal behavior (e.g., Cunha \& Gonçalves, 2013; Fowler \& Westen, 2011; Huss \& Ralston, 2008; Loinaz, 2014). Identifying offenders who commit multiple forms of offending, may have important policy implications because these individuals might be the most difficult to treat and might be responsible for disproportional rates of recidivism, potentially depleting public resources (Milaniak \& Widom, 2015). Further, professionals involved in assessing the risk posed by IPV offenders are not solely concerned with the likelihood of new IPV offending but also with the offender's risk of committing any new criminal acts. Little is known about the extent and nature of the nonspecialization of IPV offenders' criminal careers. Some IPV offenders may be similar to the broader criminal population, which exhibits a number of criminal career trajectories including one characterized by chronic and high rates of more than one type of offense (e.g., Piquero et al., 2006; Piquero, Farrington, Fontaine, Vincent, Coid, Ullrich, 2012; Theobald, Farrington, Coid, \& Piquero, 2015). For example, Piquero, Theobald, and Farrington (2013) reported that, among 319 men from a longitudinal cohort study, chronic criminal offending was associated with the highest rates of self-reported IPV. In the present research, we examined criminal careers among men sampled in a different way, from police occurrence reports of an assault on an intimate partner during a selected time period. We used this assault date as an index date to examine domestic and other types of offending in two separate, pre-index and post-index time periods. We identified pre-index career trajectories 
based on types of offending, and tested whether post-index IPV and other recidivism was predicted by pre-index criminal trajectory or by an IPV-specific risk assessment tool. This research was intended to add to the literature by studying criminal careers among IPV offenders who come to the attention of police for IPV, compared with Piquero et al.'s research which measured IPV by self-report. We also sought to address a potential methodological problem with previous research whereby some ostensibly non-IPV offenses could have been associated with intimate partners as victims; in the current study we were able to explore whether the apparent non-specialization of IPV offenders’ criminal careers might be attributable to ostensibly non-domestic recidivism that actually targets intimate partner victims.

\section{The Importance of General Criminal Offending in IPV Offender Histories}

Pre-index criminal offending (i.e., criminal offending prior to an IPV event) has been shown to have a positive association with post-index IPV recidivism, and has been incorporated as risk factors on specialized tools for assessing risk of IPV recidivism (e.g., Helmus \& Bourgon, 2011; Hilton, Popham, Lang, \& Harris, 2014; Messing \& Thaller, 2013; Nicholls, Pritchard, Reeves, \& Hilterman, 2013; Richards, Jennings, Tomsich, \& Gover, 2013; Stansfield \& Williams, 2014; Storey, Kropp, Hart, Belfrage, \& Strand, 2014). Furthermore, in their studies of IPV offenders’ criminal careers, Buzawa and Hirschel (2008) and Richards et al. (2013) reported that established predictors of general criminal offending, such as substance use, physical violence, weapon use, and younger age, were more prevalent among those with prior and recidivistic IPV. Piquero and colleagues (2013) also reported that childhood and adolescent personal and sociodemographic characteristics (27 items such as low school achievement, childhood troublesomeness, criminal parent, low socioeconomic status) associated with general criminal offending and predicted reports of subsequent IPV; however, these variables had no 
added statistical association with IPV once the lifetime general criminal career trajectory was considered. Emerging evidence suggests that specialized IPV risk assessment tools can predict general recidivism (Hilton, Harris, Popham, \& Lang, 2010), but their association with IPV offenders’ criminal career trajectories has not yet been examined. In the present study, we extended this research by testing whether a criminal career trajectory based on type of offending prior to the index assault predicted similar post-index trajectory groupings among IPV offenders.

These two lines of emerging research - the ability of criminal history to predict IPV, and evidence for general criminality among men who commit IPV - provide an empirical rationale for anticipating that tools designed to predict IPV recidivism would also predict IPV offenders' general criminal outcomes. That is, there appears to be some overlap in the predictors of general criminal outcomes and IPV recidivism, and this phenomenon may be of practical value in the selection of risk assessment tools that are appropriate to both the population and outcomes of interest. On one such tool, the Ontario Domestic Assault Risk Assessment (ODARA; Hilton et al., 2004) four of the 13 items, selected by actuarial methods in a follow up of men with a police record of assault against a female marital or cohabiting partner, pertain to an IPV offender's nonIPV criminal behavior: prior non-IPV violence, police report of such violence, prior custodial sentence, and conditional release failure (Hilton et al., 2004). A fifth item, substance abuse, concerns aspects of alcohol or drug use that may be related to criminal, relationship, or other matters. The ODARA was found to predict general recidivism among IPV offenders drawn from an incarcerated population (Hilton, Harris, Popham, \& Lang, 2010). In the present study, we further tested the ODARA's ability to predict general offending outcomes by examining its association with criminal career trajectories and a broader range of types of recidivistic offenses than previously studied, including stalking, sexual assault, and nonviolent offenses. 


\section{Previous Longitudianl Research on IPV Offenders’ Careers}

Few previous studies have examined pre- and post-IPV criminal careers. Buzawa and Hirschel (2008) studied offenders in three U.S. states arrested for an intimate partner assault and compared those who had either no prior offending, prior nonviolence only, or prior violent offending; offenders with a prior violent or nonviolent criminal history were substantially more likely to be rearrested for any offense during a follow up of three to five years. In a 10-year follow up of 317 men adjudicated for domestic violence in Massachusetts, Richards et al. (2013) reported that a prior history of domestic violence significantly increased the odds of subsequent non-domestic violent and nonviolent offenses. Together, these studies provide growing evidence of the non-specialization of criminal careers among many IPV offenders.

A potential methodological problem occurs if the nonviolent offenses committed by IPV offenders actually involve their intimate partners as victims. For example, violations of conditional release could include contacting an intimate partner contrary to the terms of probation or a court-issued restraining order, and break and enters could be committed with the intention of stealing or damaging a former partner's property or otherwise intimidating the partner. Under such circumstances, the apparent association of IPV history with subsequent nondomestic, nonviolent offending could be attributable to post-separation offenses specifically targeting a partner and not an indication of more general criminal offending. In the present study, therefore, we obtained police reports of offenses occurring after the IPV index assault in order to identify the victims of these offenses and determine whether they had an intimate relationship with the offender.

\section{Hypotheses}


The current study took place in Canada and the sample was restricted to men who came to the attention of the police for an assault or credible threat of harm on an intimate partner (marital, cohabiting, or dating). As described above, many IPV offenders do not appear to specialize in their offenses and serious IPV offenders are among the most likely to engage in other types of criminal behavior. Therefore, we hypothesized:

1. The majority of IPV offenders will not exhibit specialization; that is, most will have a pre-index criminal record for non-IPV offenses.

The current sources of information included all criminal charges occurring prior to the index assault. As described above, many IPV offenders may be similar to general offenders, some of whom exhibit chronic criminal offending, and criminal offending can predict post-index IPV. Therefore, we hypothesized:

2. Pre-index assault criminal career trajectory will predict post-index criminal career trajectory as well as IPV recidivism specifically.

The current study followed offenders for seven years after the index assault. As described above, general offending can predict post-index IPV and there is emerging evidence that IPV risk assessment tools can predict non-IPV recidivism. Therefore, we hypothesized:

3. The ODARA will predict IPV recidivism and the post-index criminal trajectory.

We also explored the extent to which ostensibly non-domestic offenses occurred in the context of an intimate relationship between the victim and offender; there is no empirical basis for a directional hypothesis, but we aimed to better understand the focus of IPV offenders postindex offending, beyond what is known from prior research.

\section{Method}


This study was reviewed and approved by the first author's institutional research ethics board. It was also subject to a research agreement between the first author and the second author's institution that outlined access to information and data storage.

\section{Data Sources}

All variables were coded from electronic records management systems. One was a police system containing detailed occurrence and general police reports of all incidents documented by a Canadian provincial police service that directly serves large and small communities. The other records system was the national record of criminal charges, convictions, and dispositions maintained by the Canadian Police Information Centre (CPIC).

The information sources were accessed by employees of the police service who were trained in using these information systems. The collected information was coded by research assistants, who were familiar with reading and interpreting this type of data. Police and criminal records were coded in a secure area of the police service and de-identified coded data were maintained on a secure server drive. All persons viewing the information had passed a security check requiring fingerprint identification. Research assistants coding the information had at minimum an undergraduate degree in psychology and some had formal positions within the police service in a research capacity.

\section{Sample}

The study sample consisted of 93 cases of IPV drawn from the police records management system. All cases involved an occurrence report filed between October 2004 and February 2005 pertaining to an IPV incident (the index assault), by an adult male offender against a female marital, cohabiting, or dating partner (current or past) following either police attendance at the incident or the subsequent attendance at a police service location by the victim. 
Our initial search was not limited to male-to-female IPV; 5 cases involving female offenders or same-sex relationships were identified in the records management system in that time. We excluded them from the present study to maintain sample homogeneity.

The sample was in part a convenience sample, based on a time frame for which we had funding for salaries. Within that timeframe we reviewed the police report database every two weeks, selecting only cases that met the criteria for inclusion during the offender's most recent occurrence within the two week period. This sampling permitted a prospective follow-up design, and is an improvement over previous research with the ODARA which sampled from earlier occurrence reports if the most recent one did not meet inclusion criteria (Hilton et al., 2004).

\section{Measures}

Index Assault Criteria. To qualify for inclusion in this study, the case had to include an incident occurring in October 2004 to February 2005 that met the eligibility criteria for scoring the ODARA. That is, the incident had to involve physical contact (assessed using the Revised Conflict Tactics Scale, CTS-2; Straus, Hamby, Boney-McCoy, \& Sugarman, 1996) or a credible threat of death made with a weapon in hand in the presence of the victim, who was a current or former intimate partner. This occurrence was defined as the index assault for this study and was identified by a research assistant reading the police occurrence reports, which described the incidents and involved parties in detail. The CTS-2 is a widely used measure with 12 items on the physical violence subscale (e.g., slapped, beat up) with good internal consistency (alpha = .86; Straus et al., 1996). In self-report research the CTS-2 has been a sensitive measure of detecting violence and shown construct validity with reports of injury and other outcomes (e.g., Straus \& Mickey, 2012). In archival studies, it has been scored reliably (e.g., Hilton et al., 2004) 
and shown good ability to identify cases of IPV (Lipsky, Cristofalo, Reed, Caetano, \& RoyByrne, 2012).

Index Assault Characteristics. We coded victim injury and other characteristics of the index assault for descriptive purposes. We coded victim injury at the index assault using the injury scale from the Danger Assessment (e.g., Snider, Webster, O'Sullivan, \& Campbell, 2009) which focuses on the severity of injury as well as the injury scale from the Violent Risk Assessment Guide (VRAG; Quinsey, Harris, Rice, \& Cormier, 2006; Harris, Rice, Quinsey, \& Cormier, 2015) which also captures the medical intervention required. The Danger Assessment injury scale has possible scores of 1-no injuries and/or lasting pain; 2-bruises, cuts, and/or continuing pain; 3-severe contusions, burns, broken bones; 4-head injury, internal injury, permanent injury; 5-wounds from weapon; no cases in our sample scored above 3. The VRAG injury scale has possible scores of 1-no injury; 2-slight injury, no weapon; 3-slight injury, weapon; 4-treated in clinic and released; 5-victim hospitalized at least one night; 6-death; 7death and post-death mutilation; no cases in our sample scored above 5. Although the Danger Assessment injury scale was designed for victim interview, both scales have previously been used in archival studies of IPV with good inter-rater reliability (e.g., Hilton et al., 2004). In this study, the scales were coded by a research assistant using the police occurrence reports of the index assault.

We coded whether the offender was charged for any offenses pertaining to the index assault, using the police occurrence report and the offender’s history of criminal charges and convictions. We also coded relationship information, including the victim and offender's marital status at the time of the index assault, when they began dating or living together, and any known separations prior to the index assault, but did not hypothesize that these variables would add to 
the predictive accuracy of the ODARA in the present study because they had failed to in previous research (e.g., Hilton et al., 2004); they were not significantly correlated with IPV recidivism in the present study and we report them here only to fully describe our study.

Ontario Domestic Assault Risk Assessment (ODARA). Research assistants coded the ODARA (Hilton et al., 2004; Hilton, Harris, \& Rice, 2010) based on events at or prior to the index assault, using the police occurrence reports and the criminal record. The ODARA is an actuarial assessment developed specifically to assess the risk of IPV recidivism among domestic offenders using information contained in police and criminal records. It has been shown to predict IPV recidivism with a moderate effect size on average (AUC = .66) (e.g., Helmus \& Bourgon, 2011; Messing \& Thaller, 2013). It was developed and cross-validated using police records (Hilton \& Harris, 2009; Hilton et al., 2004; Hilton, Harris, Rice, Houghton, \& Eke, 2008) but later validated with male and female correctional offenders (e.g., Hilton, Harris, Popham \& Lang, 2010; Hilton et al., 2014; Rettenberger \& Eher, 2012). The ODARA includes four items pertaining to an IPV offender's non-IPV criminal behavior (i.e., prior non-IPV violence, police report of such violence, prior custodial sentence, and conditional release failure - potentially including violations of court-issued no-contact orders) but also eight items specific to the nature of the index offense (i.e., threat of harm, confinement), the offender-victim relationship (i.e., the offender's children, the victim's prior children, police report of prior IPV, and IPV during the victim's pregnancy), and the victim's circumstances (i.e., concern about future assault, barriers to support). A thirteenth item concerns aspects of substance abuse related to criminal, relationship, or other matters. We scored each item as 0-not present, 1-present, using the scoring manual criteria (Hilton, Harris, \& Rice, 2010). 
Pre-Index Criminal History. We coded information about all pre-index charges or convictions listed in police reports and criminal records, including occurrence dates, charges, and dispositions, where available. We categorized criminal charges as violent or nonviolent according to the Cormier-Lang System for Quantifying Criminal History (Quinsey et al., 2006; Harris et al., 2015). The Cormier-Lang system has been used extensively in archival research involving offenders and forensic patients where it has been scored with excellent reliability (e.g., $r>$.80; Harris et al., 2015), shown concurrent validity with other criminal history measures (e.g., $r=.31$ - .60; Jung, Daniels, Friesen, \& Ledic, 2012), and been significantly associated with IPV risk (e.g., Hilton et al., 2004). Examples of nonviolent offenses according to the Cormier Lang system include theft, threatening, break and enter and other nonsexual offenses involving no physical contact with a victim. We further subdivided nonviolent offenses into threats (e.g., utter threat of death), criminal harassment (e.g., stalking behaviors), mischief (e.g., destruction of property), and failure on conditional release (e.g., charges for breach of probation, failure to attend court) for a more detailed examination of the diversity of offending. Examples of violent offenses according to the Cormier Lang system include homicide, kidnapping, sexual assault, and armed robbery. We also further examined the character of violent and sexual offenses by subdividing them into violent (assault, forcible confinement, and other non-sexual offenses), and sexual offenses including separate categories for contact sexual offenses (e.g., sexual assault) and noncontact sexual offenses (e.g., child pornography). We also counted the total number of documented incidents of each type of offense.

We noted any juvenile offending prior to the index assault, which would have permitted us to replicate previous research (e.g., Piquero et al., 2013), but there were no offenders whose only 
pre-index record was for juvenile offenses, so we did not include juvenile offending in the analysis of careers.

Post-Index Recidivism. To code recidivism, we examined police reports and criminal records for each offender seven years after the index assaults, in the spring of 2012. We coded every post-index offense documented in police reports or the criminal record. Some incidents in police occurrence reports had not yet been resolved (i.e., no criminal charge or conviction appeared on the record yet) so we coded all occurrences regardless of charges or convictions, excluding only reports without a clear offense (e.g., a consensual fight between two males). We coded occurrence dates, charges, and disposition where available for nonviolent, violent, and sexual offenses, and then we subcategorized them into the same offense sub-types as used for pre-index offenses. For new breaches and failures of release, we also noted details of the offense such as whether the offender was breached for contacting the index assault victim. For all new offenses, we coded the offender's relationship to the victim, so we could identify when they involved an intimate partner. We also coded whether substances (i.e., drugs or alcohol) were used by the offender at the time of the offense if documented in the occurrence report.

Time at Risk for IPV Recidivism. To measure time at risk, we calculated the difference between the index assault and the date when the police and criminal records were checked for follow up in 2012, or (for IPV recidivists only) between the index assault and the date of the first incident of IPV recidivism. We subtracted time in custody, whether for offenses at the time of the index assault or any subsequent offense, so the time at risk represented an offender's opportunity to reoffend while in the community.

\section{Procedure}


Coding was conducted at two time periods, the first proximal to the index assault date and the second after seven years. A research assistant identified all IPV occurrence reports from October 2004 to February 2005 within two weeks of their appearance in the police reporting system, and coded index assault variables, including a preliminary score on the ODARA using the police occurrence reports. We had planned a fully prospective design to test the ODARA's predictive accuracy, but a new records management system had been introduced at the time of the index assault data collection, requiring a separate step to review offenders’ additional criminal records; we later realized not all records had been reviewed and consequently, different research assistants later accessed full criminal records and rescored the ODARA to ensure completeness. This step was taken in 2012 when follow-up data collection was conducted. These assistants also coded all post-index offending in 2012. A cross-over procedure was used to separate and code the records in order to mask index and pre-index coding from post-index coding. Two assistants separated records for the index assault and pre-index offenses from records for post-index offenses, for one half of the cases, then coded index assault and pre-index variables for the other half that they had not separated, masked to outcome. When this coding was completed, they then switched cases and coded post-index variables. A third research assistant coded all post-index incidents related to an intimate partner victim, regardless of violence or criminal charges.

We created trajectory groups for pre-index offenses and post-index offenses separately. Offenders were divided into four groups indicating: 1- no charges, 2 - nonviolent charges only, 3 - violent charges without IPV, and 4 - violent charges for IPV. We assessed pre-index IPV based on having a prior assault against the index assault victim or another partner documented in police or criminal records and being charged with a violent offense. 


\section{Inter-Rater Reliability}

Inter-rater reliability (IRR) was assessed in several ways. In 2004-2005, a second research assistant independently coded 10 cases (11\%) to assess IRR of index assault variables and initial ODARA scores. In 2012, the two research assistants coding in the cross-over procedure subsequently coded twenty (22\%) of each other's cases independently, providing IRR tests of pre- and post-index variables and completed ODARA scores. The first author also independently coded post-index intimate partner-related incidents in ten cases (11\%) in 2012. IRR coefficients for pre-index offending, post-index offending, and ODARA scores were $r \geq .80$. Completed ODARA scores were consistent with preliminary scores $(r=.85, p<.001)$ but generally slightly higher (mean adjustment $=1$ point) due to the availability of complete criminal records; the results below are based on the completed scores.

\section{Statistical Analysis}

We examined the descriptive data in terms of offender and victim age, relationship characteristics, and index assault details. We also calculated time at risk overall and for each type of offense, calculating the number of days between the index assault date and the date of the first post-index incident.

Hypothesis 1 (non-specialization). We examined the overall percentage of offenders charged with each type of offense prior to the index assault. We illustrated the incidence of offending in a series of hazard curves summarizing, for each type of offense, the cumulative percentage of offenders committing their first incident within or before a given number of years before the index assault date.

Hypothesis 2 (pre-index career trajectory predictions). We conducted chi-squared analyses to test whether the pre-index trajectory variable predicted post-index criminal offending trajectory or the occurrence of IPV recidivism. 
Hypothesis 3 (ODARA predictions). We conducted a logistic regression of the ODARA and post-index trajectory to test whether the ODARA score distinguished among the four types of criminal outcomes in the trajectory. We conducted an ROC analysis of the ODARA on the occurrence of post-index IPV recidivism to test whether the ODARA predicted this dichotomous outcome. We also tested the ODARA's predictive accuracy for other types of offending using ROC analyses. We illustrated the incidence of post-index offending in a series of survival curves summarizing, for each type of offense, the cumulative percentage of offenders committing their first incident within or before a given number of years after the index assault date.

We examined the occurrence of post-index non-IPV offenses that involved an intimate partner victim using descriptive statistics.

\section{Results}

\section{Sample Characteristics}

The mean age of offenders at the index assault date was 36.5 years $(S D=12.5)$ with a range of 19 to 76 years. The mean age of index assault victims was 33.1 years $(S D=12.1)$ years with a range of 15 to 75 . Over half the offenders and victims had ever lived together without marriage ( $n=51,55 \%$ ), one third had been married ( $n=34,37 \%)$, and eight ( $9 \%$ ) had a dating relationship. At the time of the index offense, offenders and index victims were cohabiting $(n=$ 48, 52\%), followed by married and living together ( $n=30,32 \%)$, dating or former dating partners $(n=8,9 \%)$, separated after marriage or living together $(n=5,5 \%)$ or persons with a former intimate relationship continuing to live under one roof $(n=2,2 \%)$.

All offenders had committed a physical assault on their intimate partner on the index assault date. The index assault included minor violence as defined by the CTS-2 (Straus et al., 
1996) in 82 cases (88\%) and severe violence in 43 cases (46\%). Two index assaults involved sexual violence against the partner. The victim was physically injured in over half the index assaults $(n=49,53 \%)$, not injured $25(27 \%)$, and injury was undetermined in 19 cases (20\%). On the Danger Assessment injury scale, the mean score was $1.68(S D=0.50)$, close to the rating for bruises, cuts or continuing pain, and only one case (1\%) resulted in severe contusions, broken bones or burns. On the VRAG injury scale, the mean score was $2.09(S D=1.10)$, equivalent to slight physical injury, although medical treatment or hospitalization was required in 14 cases (15\%). Criminal charges were laid against the male offender pertaining to the index assault in 88 cases (95\%), and the female was also charged in two (i.e., there were dual charges). In the remaining five cases the offender was diverted to the mental health system $(n=1)$, arrested and released after an investigation ( $n=2)$, or not arrested as the victim sought police advice but did not wish to provide a statement $(n=2)$. Of the 88 cases with charges, post-charge information was available for 83; 58 were convicted of at least one charge pertaining to the index assault (most of these for assault, 65\%), but in two cases an assault charge was stayed in favor of a peace bond or other criminal justice outcome.

Offenders were followed up for a mean of 7.48 years $(S D=0.11)$ from the index assault date, with a range of 7.28-7.69 years. All had time at risk in the community, ranging from 97 days to 7.83 years, with a mean of $6.37(S D=2.13$ years $)$. In this time, 22 offenders $(24 \%)$ had a police documented new IPV offense (Table 1), 14 of whom (64\%) were convicted and five (23\%) were charged. Six offenders (7\%), recidivated with a sexual assault; in two cases the victim was a current or past intimate partner (which we classified as IPV recidivism). Half the total sample ( $n=48,52 \%$ ) had a documented failure on conditional release (not necessarily related to the index assault). Substance use was involved in recidivism for 36 offenders (39\%). 


\section{Hypothesis 1. Most offenders will have a pre-index criminal record for non-IPV offenses.}

Most offenders ( $n=66,71 \%)$ had at least one pre-index criminal charge, and 60 (65\% had a pre-index charge for non-violent offending. As nonviolent offending excludes IPV, and it occurred in more than $50 \%$ of cases (binomial test of difference from $50 \% p=.006$ ), this result provides evidence consistent with the hypothesis

The distribution of pre-index trajectories was: 27 offenders (29\%) had no pre-index charges, 17 (18\%) had only nonviolent charges pre-index, 10 (11\%) had charges for pre-index violent offending without IPV, and 39 (42\%) had pre-index charges of violence and IPV. Being in the latter category did not preclude having charges for other violence or for nonviolence; indeed, of the 39 offenders in the pre-index IPV trajectory, the majority ( $n=34,87 \%)$ also had pre-index charges for non-violent offenses. Figure 1a shows the accumulation of different types of offending pre-index (hazard curve). It illustrates the prevalence and variety of criminal offending not limited to IPV, and the similarity of the trends in the hazard curve between IPV and the other types of offending. These findings are consistent with the hypothesis of nonspecialization.

\section{Hypothesis 2. Pre-index criminal career trajectory will predict post-index criminal trajectory and IPV recidivism.}

Most offenders ( $n=58,62 \%)$ had at least one post-index criminal charge which consisted primarily of conditional release failures (52\%) and nonviolent offending (43\%). The distribution of post-index trajectory groups was: 38\% no recidivism, 24\% nonviolent recidivism only, 15\% violent recidivism without IPV, and 24\% IPV recidivism. Most offenders committed at least one non-IPV offense at some point, and 37\% committed non-IPV offenses both pre- and post-index. All but three of the 22 IPV recidivists had additional, nonviolent recidivism. In support of our 
hypothesis, pre-index trajectory was significantly associated with post-index trajectory group, $\chi^{2}$ $(9, N=93)=18.56, p=.029$, but contrary to our hypothesis was it not significantly associated with IPV recidivism specifically, $\chi^{2}(3, \mathrm{~N}=92)=4.66, p=.198$. Thus, apparent pre-index specialization in violent or nonviolent offending was related to similar outcomes post-index, but was not an indicator of risk for IPV recidivism. Figure $1 \mathrm{~b}$ shows the cumulative post-index failure rate for the different types of offending (survival curve).

\section{Hypothesis 3. The ODARA will predict IPV recidivism and the post-index criminal} trajectory.

The mean raw ODARA score for the full sample was $5.19(S D=2.83), 95 \% \mathrm{CI}=[4.62$, 5.77], range $0-11$, median $=5$, with an approximately normal distribution, skew $=.263(S E=$ $.249)$, kurtosis $=-.920(S E=.493)$. ODARA scores for 14 cases $(15 \%)$ were prorated according to the published criteria based on missing items, and the sample mean ODARA score after prorating these cases was $5.36(S D=2.77), \mathrm{CI}=[4.79,5.93]$, range $0-11$, median $=5$, skew $=$ $.124(S E=.249)$, kurtosis $=-.891(S E=.493)$. Because the ODARA distribution was not significantly changed by this prorating, and previous research indicates lower predictive accuracy for prorated scores, likely due to loss of information (Hilton, Harris, Popham \& Lang, 2010), the remaining results are reported for the raw score only.

With respect to IPV outcomes, ODARA score predicted the occurrence of any IPV recidivism, $\mathrm{AUC}=.671(\mathrm{SE}=.061), 95 \% \mathrm{CI}=[.558, .793], r=.256, p=.016$, consistent with our hypothesis. In addition, ODARA score was correlated with the number of post-index domestic incidents (regardless of violence) in police occurrence reports, $r(89)=.30, p=.004$, corresponding to a medium effect size (e.g., Rice \& Harris, 2005). ODARA score was positively but not significantly correlated among the 22 IPV recidivists with the seriousness of the criminal 
justice outcome for recidivistic incidents, $r(20)=.28, p=.217$, severity of injury at the first IPV recidivistic incident as measured on the Danger Assessment injury scale, $r(19)=.15, p=.538$ the VRAG injury scale, $r(20)=.09, p=.712$, and shorter time at risk until IPV recidivism, $r(21)$ $=.07, p=.743$.

With respect to recidivism more generally, the ODARA score significantly distinguished the post-index trajectory groups, consistent with our hypothesis, multinomial logistic regression $\chi^{2}(33)=52.94, p=.015$. It was also a significant predictor of all types of recidivism (Table 1 ). Exploration of Victim-Offender Relationship in Nonviolent Offenses

More than half the offenders ( $n=55,59 \%)$ had a post-index nonviolent offense. In 30 of these cases (55\%) the victim was a current or former intimate partner. In some cases the intimate nonviolent offenses included making death threats to the victim (the index assault victim or another intimate partner) or violating a no-contact order, whereas others were property offenses such as breaking into the victim's residence and theft of the victim's vehicle. Threats were also involved in some non-intimate nonviolent offenses, and others involved impaired driving, obstruct police, failure to appear for court and escape lawful custody. In a post-hoc analysis, ODARA score was not significantly higher among those men whose nonviolent recidivism involved an intimate partner, $M=6.53(S D=2.83)$ vs. $M=5.64,(S D=2.61), 95 \% \mathrm{CI}=[-0.59$, 2.37], $t(53)=1.21, p=.232$, ns.

\section{Discussion}

In this sample of 93 men with a police record of intimate partner assault (IPV) nearly two thirds of the offenders had criminal charges prior to the IPV index assault date. In a seven and a half year follow up, most offenders incurred a police report for some type of post-index recidivism, which included IPV for a minority. Recidivists committed new offenses documented 
across a broad range of post-index offense categories, each of which was predicted by the ODARA, an instrument designed to assess risk of IPV recidivism. Pre-index career trajectory group (none, nonviolent, violent, or violent with IPV) did predict the same offense groupings post-index but not IPV recidivism specifically. The finding that a specialized IPV risk assessment instrument predicts a range of other criminal outcomes complements previous research showing that criminal history is important to IPV risk assessment. That this tool was a better predictor of recidivism than was the broad category of criminal history is consistent with risk assessment research showing that the premise that "past offending predicts future offending" can be improved upon, and raises the possibility that such tools might be valuable in criminal career research warranting more nuanced measures of index time-point risk.

The present study adds to the emerging literature suggesting that IPV offenders have broad ranging criminal careers. Piquero et al. (2013) reported that chronic criminal offending was associated with the highest risk for self- and partner-reports of IPV across the same time frame. We found a similar association in the pre-index period between criminal trajectory and official reports of IPV, although not between pre-index criminal offending trajectory and postindex IPV. Richards et al. (2013) reported that pre-index IPV was associated with non-IPV recidivism, and further to this we found that IPV risk (ODARA score) was associated with nonIPV recidivism across a range of offense types. Research on batterer types has led to the identification of a subgroup of offenders who exhibit general antisociality as well as relatively severe and persistent IPV, and work with official IPV offender samples points to the predominant explanatory power of general antisociality (e.g., Harris, Hilton, \& Rice, 2011). Our finding that the ODARA, an actuarial risk assessment for IPV recidivism, predicted non-IPV recidivism among IPV offenders suggests that this antisocial type is to be found among those at 
higher risk of IPV recidivism. Thus, the present study offers a consilience between the criminal careers, risk assessment, and typology literatures. It also demonstrates the extent to which specialized IPV tools can be used for IPV violence risk assessment as well for predicting reoffending overall among men arrested for IPV.

Although future IPV was predicted by the ODARA, nonviolent offending against intimate partners was not. Just over half of the offenders with nonviolent recidivism had committed a threat, property offense, or no-contact violation against an intimate victim. The ODARA did not statistically distinguish those men who nonviolently offended against intimate rather than non-intimate victims. This result provides further evidence that general criminal offending by IPV offenders cannot be fully explained by acts against intimate partners, a finding that helps resolve a methodological question regarding research on the criminal careers of IPV offenders.

The present study provides a cross-validation of the ODARA in a previously unreported sample of men drawn from police records based on an assault against a female partner, including some who had not previously lived together. Only a small percentage of offenders committed IPV recidivism within a year of the index assault date. The cumulative survival rate, on the other hand, declined at only a slightly decreasing rate without plateauing within the seven and a half years’ follow up. This finding lends further support to Klein and Tobin's (2008) conclusion that short term follow-up periods may not accurately illustrate offenders' risk of recidivism, beyond short-term desistance or suppression effects of intervention.

\section{Limitations}

This study relied on police and criminal records, and we did not conduct offender interviews or have collateral reports which could provide further information on the offenses. 
The police records contained extensive description of the events, involved parties, and background regarding occurrence. On the other hand, official records of criminal history are generally understood to underestimate offending and not all charges and convictions are listed, such as diverted offenses, or charges that are purged after a pardon or offense-free time after adolescence. Furthermore, we did not have data from metropolitan police services or those outside the province; hence, there might be data missing on some police reported pre-index or post-index occurrences which we were unable to include in the study.

A related limitation is that the sample was restricted to a subgroup of IPV perpetrators: those who were the subject of a police report for IPV, almost all of whom were charged for the offense at a given point in time, the index assault. The current results cannot be assumed to apply to all men who assault their intimate partner, particularly those who fall into the "family only” or disturbed, borderline, or dependent batterer types (although the latter can also be found in adjudicated populations; e.g., Cunha \& Gonçalves, 2013).

The small sample size may have limited the power to detect other statistical findings. Nevertheless, significant results were observed, particularly for the prediction of post-index recidivism.

As described in the method, the ODARA score was recalculated at the time of the followup data collection due to limited criminal information available at the time of the index assault, resulting in a quasi-prospective design for the test of the ODARA's predictive accuracy. Nevertheless, the two scores yielded excellent masked reliability, and results using original, incomplete scores were highly consistent with those reported here.

\section{Recommendations for Practice}


Evidence for the non-specialization of criminal careers among IPV offenders bears implications for clinical and correctional interventions. Treatment programs designed for batterers have yielded equivocal results (e.g., Gondolf, 2011; Radatz \& Wright, 2015; Sartin, Hansen, \& Huss, 2006). A diversity of approaches to treatment exists (Gondolf, 2011), yet they generally remain homogenous with respect to the treatment of IPV as a specialized offense rather than being informed by offenders’ criminal careers and generally antisocial behaviors such as substance abuse (Richards et al., 2013; Ritter, Kivisto, Handsel, \& Moore, 2014). For IPV offenders who engage in broader criminal offending, treatments could endeavor to modify those behaviors whose change is most strongly associated with reductions in offending, such as associating with criminal peers, employment performance, and alcohol use (e.g., Wooditch, Tang, \& Taxman, 2014). We concur with Radatz and Wright (2015) who argue that the RiskNeed-Responsivity principles of effective correctional intervention (e.g., Andrews \& Bonta, 2010) could be a helpful guide to developing interventions for men who commit IPV as much as to the broader population of offenders.

Non-specialized offending underscores the importance of criminal history in the assessment of risk for IPV recidivism. Several measures to assess risk of IPV are available that are intended as a victim or offender interview rather than for scoring from official police and criminal reports (e.g., Messing, Amanor-Boadu, Cavanaugh, Glass, \& Campbell, 2013; Holtzworth-Munroe, Beck, \& Applegate, 2010). Supplementing these interviews with criminal record checks, or informants’ (e.g., victim, family) report of the offender's criminal history, might improve these tools’ discrimination among IPV recidivists. Furthermore, the present study suggests that, when there is a particular need to assess the risk of IPV (such as when there is concern for a particular victim who is the partner of an IPV offender) as well as to assess risk of 
violence in general, the selection of a specialized risk assessment instrument may be simplified by the availability of tools validated for both outcomes. The present paper provides some support for this practice by demonstrating the ODARA's predictive accuracy for a variety of criminal outcomes among IPV offenders.

\section{Recommendations for Research}

The present study adds to the literature on criminal careers among IPV offenders that characterizes pre- and post-index careers in terms of simple categorical trajectories. As this study was based on criminal record data, future research could examine whether similar patterns would emerge from perpetrator self-report. Details gathered through self- or victim-reports might permit the investigation of more complex patterns, such as the multidimensional (type of abuse, frequency) trajectories constructed by Jones, Heckert, Gondolf, Zhang, and Ip (2010) to track changes in abuse behaviors over time. In official offender populations, examining changes affected by criminal justice interventions, treatment modalities, or their combination, could be a productive avenue of research. Particular attention is warranted to the adoption of Risk-NeedResponsivity principles, and their benefits and limitations with respect to the response to IPV. Changes in intimate partner relationship status over time might also affect criminal and IPV careers. In particular, IPV offenders may provide an interesting opportunity for investigation of the concept of "good marriages” (e.g., Laub, Nagin, \& Sampson, 1998). That is, settling into marriage and work is thought to represent a turning point in the life course, whether as a structural change in offenders' lives that promotes desistance from a criminal career or as a signpost of psychological change associated with readiness to desist (e.g., Laub, Nagin, \& Sampson, 1998; Nakamura \& Bucklen, 2014). Research is needed to determine whether this applies to men who assault their intimate partners, particularly considering that a majority of 
their nonviolent offending involved an intimate partner victim. For IPV offenders, it may be that entering an intimate relationship has little impact on what is already a diversified criminal career. 


\section{References}

Andrews, D. A., \& Bonta, J. (2010). The psychology of criminal conduct (5th Edn.). New Providence, NJ: Anderson.

Buzawa, E. S. \& Hirschel, D. (2008). Domestic violence: The beginning, continuation, or final act in a criminal career? Victims \& Offenders, 3, 391 - 411. doi: 10.1080/ 15564880802338518

Cunha, O., \& Gonçalves, R. A. (2013). Intimate partner violence offenders: Generating a databased typology of batterers and implications for treatment. European Journal of Psychology Applied to Legal Context, 5, 131-139. doi:10.5093/ejpalc2013a2

Gondolf, E. W. (2011). The weak evidence for batterer program alternatives. Aggression and Violent Behavior, 16, 347-353. doi:10.1016/j.avb.2011.04.011

Fowler, K. A., \& Westen, D. (2011). Subtyping male perpetrators of intimate partner violence. Journal of Interpersonal Violence, 26, 607-639. doi:10.1177/0886260510365853

Harris, G. T., Hilton, N. Z., \& Rice, M. E. (2011). Explaining the frequency of intimate partner violence by male perpetrators: Do attitude, relationship, and neighborhood variables add to antisociality? Criminal Justice and Behavior, 38, 309-331. doi:10.1177/0093854810397449.

Harris, G. T., Rice, M. E., Quinsey, V. L., \& Cormier, C. (2015). Violent Offenders: Appraising and Managing Risk, $3^{r d}$ Edn. Washington, DC: American Psychological Association.

Helmus, L. \& Bourgon, G. (2011). Taking stock of 15 years of research on the Spousal Assault Risk Assessment Guide (SARA): A critical review. International Journal of Forensic Mental Health, 10, 64-75. doi:10.1080/14999013.2010.551709 
Hilton, N. Z. \& Harris, G. T. (2009). How nonrecidivism affects predictive accuracy: Evidence from a cross-validation of the Ontario Domestic Assault Risk Assessment (ODARA). Journal of Interpersonal Violence, 24, 326-337. doi:10.1177/0886260508316478

Hilton, N. Z., Harris, G. T., Popham, S., \& Lang, C. (2010). Risk assessment among incarcerated domestic offenders across follow-up times and case criteria. Criminal Justice and Behavior, 37, 815-832. doi:10.1177/0093854810368937

Hilton, N. Z., Harris, G. T., \& Rice, M. E. (2010). Risk assessment for domestically violent men: Tools for criminal justice, offender intervention, and victim services. Washington, DC: American Psychological Association.

Hilton, N. Z., Harris, G.T., Rice, M.E., Houghton, R., \& Eke, A.W. (2008). An indepth actuarial risk assessment for wife assault recidivism: The Domestic Violence Risk Appraisal Guide. Law and Human Behavior, 32, 150-163. doi:10.1007/s10979-007-9088-6

Hilton, N. Z., Harris, G.T., Rice, M.E, Lang, C., Cormier, C.A., \& Lines, K.J. (2004). A Brief Actuarial Assessment for the Prediction of Wife Assault Recidivism: The Ontario Domestic Assault Risk Assessment. Psychological Assessment, 16, 267-275.

Hilton, N. Z., Popham, S., Lang, C., \& Harris, G.T. (2014). Preliminary validation of the ODARA for female intimate partner violence offenders. Partner Abuse, 5, 189-203.

Holtzworth-Munroe, A., Beck, C. J. A., \& Applegate, A. G. (2010). The mediator’s assessment of safety issues and concerns (MASIC): A screening interview for intimate partner violence and abuse available in the public domain. Family Court Review, 48, 646-662. doi:10.1111/j.1744-1617.2010.001339.x 
Huss, M., \& Ralston, A. (2008). Do batterer subtypes actually matter? Treatment completion, treatment response, and recidivism across a batterer typology. Criminal Justice and Behavior, 35, 710-724. doi:10.1177/0093854808316218

Jones, A. S., Heckert, D. A., Gondolf, E. D., Zhang, Q., \& Ip, E. H. (2010). Complex behavioral patterns and trajectories of domestic violence offenders. Violence and Victims, 25, 3-17. doi:10.1891/0886-6708.25.1.3

Jung, S., Daniels, M. K., Friesen, M., \& Ledi, D. (2012). An examination of convergent constructs among Level of Service measures and other measures. The Journal of Forensic Psychiatry \& Psychology, 23, 601-619. doi:10.1080/14789949.2012.732595

Klein, A. R., \& Tobin, T. (2008). A longitudinal study of arrested batterers, 1995-2005: Career criminals. Violence Against Women, 14, 136-157. doi:10.1177/1077801207312396

Laub, J. H., Nagin, D. S., \& Sampson, R. J. (1998). Trajectories of change in criminal offending: Good marriages and the desistance process. American Sociological Review, 63, 225-238.

Lipsky, S., Cristofalo, M., Reed, S., Caetano, R., \& Roy-Byrne, P. (2012). Racial and Ethnic disparities in police-reported intimate partner violence perpetration: A mixed methods approach. Journal of Interpersonal Violence, 27, 2144-2162.

doi:10.1177/0886260511432152

Loinaz, I. (2014). Typologies, risk and recidivism in partner-violent men with the B-SAFER: A pilot study. Psychology, Crime \& Law, 20, 183-198. doi:10.1080/1068316X.2013.770854

Messing, J. T., \& Thaller, J. (2013). The average predictive validity of intimate partner violence risk assessment instruments. Journal of Interpersonal Violence, 28, 1537-1558. doi: $10.1177 / 0886260512468250$ 
Messing, J. T., Amanor-Boadu, Y., Cavanaugh, C. E., Glass, N. E., \& Campbell, J. C. (2013). Culturally competent intimate partner violence risk assessment: Adapting the Danger Assessment for immigrant women. Social Work Research, 37, 263-275. doi:

10.1093/swr/svt019

Milaniak, I., \& Widom, C. S. (2015). Does child abuse and neglect increase risk for perpetration of violence inside and outside the home? Psychology of Violence, 5, 246-255. doi:10.1037/a0037956

Nakamura, K., \& Bucklen, K. B. (2014). Recidivism, Redemption, and Desistance: Understanding Continuity and Change in Criminal Offending and Implications for Interventions. Sociology Compass, 8, 384-397. doi:10.1111/soc4.12150

Nicholls, T., L., Pritchard, M. M., Reeves, K. A., \& Hilterman, E. (2013). Risk Assessment in intimate partner violence: A systematic review of contemporary approaches. Partner Abuse, 4, 76-168. doi:10.1891/1946-6560.4.1.76

Piquero, A. R., Brame, R., Fagan, J., \& Moffitt, R. E. (2006). Assessing the offending activity of criminal domestic violence suspects: Offense specialization, escalation, and de-escalation evidence from the Spouse Assault Replication Program. Public Health Reports, 121, 409-418.

Piquero, A. R., Farrington, D. P., Fontaine, N. M. G., Vincent, G., Coid, J., \&Ullrich, S. (2012). Childhood risk, offending trajectories, and psychopathy at age 48 years in the Cambridge Study in Delinquent Development. Psychology, Public Policy, and Law, 18, 577-598. doi:10.1037/a0027061.

Piquero, A., Theobald, D., \& Farrington, D. P. (2013). The overlap between offending trajectories, criminal violence, and intimate partner violence. International Journal of 
Offender Therapy and Comparative Criminology, 58, 286-302. doi:10.1177/ $0306624 X 12472655$

Quinsey, V. L., Harris, G. T., Rice, M. E., \& Cormier, C. (2006). Violent Offenders: Appraising and Managing Risk, $2^{\text {nd }}$ Edn. Washington, DC: American Psychological Association.

Radatz, D. L., \& Wright, E. M. (2015). Integrating the principles of effective intervention into batterer intervention programming: The case for moving toward more evidence-based programming. Trauma Violence Abuse. Advance online publication January 8, 2015, doi: $10.1177 / 1524838014566695$

Rettenberger, M. \& Eher, R. (2012). Actuarial risk assessment in sexually motivated intimatepartner violence. Law and Human Behavior, 37, 75-86. doi:10.1037/b0000001

Rice, M. E., \& Harris, G. T. (2005). Comparing effect sizes in follow-up studies: ROC, Cohen's $d$ and r. Law and Human Behavior, 29, 615-620. doi:10.1007/s10979-005-68327

Richards, T. N., Jennings, W. G., Tomsich, E. A., \& Gover, A. R. (2013). A longitudinal examination of offending and specialization among a sample of Massachusetts domestic violence offenders. Journal of Interpersonal Violence, 28, 643-663. doi:10.1177/ 0886260512455519

Ritter, K., Kivisto, A., Handsel, V., \& Moore, T. (2014). Intimate Partner Violence, PTSD, and Substance Use. In P. Ouimette \& J. P. Read (Eds.), Trauma and Substance Abuse: Causes, Consequences, and Treatment of Comorbid Disorders (2nd Edn.) (pp. 211-230). Washington, DC: American Psychological Association. 
Sartin, R. M., Hansen, D. J., \& Huss, M. T. (2006). Domestic violence treatment response and recidivism: A review and implications for the study of family violence. Aggression and Violent Behavior, 11, 425-440. doi:10.1016/j.avb.2005.12.002

Snider, C., Webster, D., O'Sullivan, C. S. \& Campbell, J. (2009). Intimate partner violence: Development of a brief risk assessment for the emergency department. Academic Emergency Medicine, 16, 1208-1216. doi:10.1111/j.1553-2712.2009.00457.x

Stansfield, R., \& Williams, K. (2014). Predicting family violence recidivism using the DVSI-R: integrating survival analysis and perpetrator characteristics. Criminal Justice and Behavior, 41, 163-180.

Storey, J. E., Kropp, P., Hart, S., Belfrage, H., \& Strand, S. (2014). Assessment and management of risk for intimate partner violence by police officers using the Brief Spousal Assault Form for the Evaluation of Risk. Criminal Justice and Behavior, 41, 256-271. doi: 10.1037/h0093948

Straus, M.A., Hamby, S.L., Boney-McCoy, S., \& Sugarman, D.B. (1996). The Revised Conflict Tactics Scales (CTS2). Journal of Family Issues, 17, 283-316.

Straus, M.A., \& Mickey, E. L. (2012). Reliability, validity, and prevalence of partner violence measured by the Conflict Tactics Scales in male-dominant nations. Aggression and Violent Behavior, 17, 463-474. doi:10.1016/j.avb.2012.06.004

Theobald, D., Farrington, D. P., Coid, J. W., \& Piquero, A. R. (2015). Are male perpetrators of intimate partner violence different from convicted violent offenders? Examination of psychopathic traits and life success in males from a community survey. Journal of Interpersonal Violence. Advance online publication. doi:10.1177/0886260515569061 
Wooditch, A., Tang, L. L., \& Taxman, F. S. (2014). Which criminogenic need changes are most important in promoting desistance from crime and substance abuse? Criminal Justice and Behavior, 41, 276-299. doi:10.1177/0093854813503543 
Table 1.

Recidivism and the Prospective Predictive Validity (Discrimination Accuracy) of the Ontario Domestic Assault Risk Assessment (ODARA)

\begin{tabular}{|c|c|c|c|c|c|c|}
\hline \multirow[b]{2}{*}{ Type of Recidivism } & \multirow{2}{*}{$\begin{array}{c}\mathrm{N}(\%) \\
\text { or Mean (SD) }\end{array}$} & \multicolumn{4}{|c|}{ ODARA } & \multirow[b]{2}{*}{$p$} \\
\hline & & AUC & $95 \%$ CI & SE & $r$ & \\
\hline & N (\%) & & & & & \\
\hline $\begin{array}{l}\text { Intimate partner violence } \\
\text { (assault on any partner) }^{\mathrm{b}}\end{array}$ & $22(24)$ & .67 & $.55, .79$ & .061 & .25 & .016 \\
\hline Any offense & $58(62)$ & .75 & $.64, .85$ & .052 & .42 & $<.001$ \\
\hline Any violent offense & 36 (39) & .65 & $.54, .76$ & .057 & .25 & .014 \\
\hline Violent or contact sex offense & $37(40)$ & .67 & $.56, .78$ & .057 & .29 & .005 \\
\hline Any nonviolent offense & $40(43)$ & .74 & $.64, .85$ & .052 & .42 & $<.001$ \\
\hline Failure on conditional release & $48(52)$ & .72 & $.62, .83$ & .053 & .39 & $<.001$ \\
\hline Stalking (criminal harassment) & $9(10)$ & .78 & $.66, .89$ & .059 & .29 & .005 \\
\hline Threats made at any offense & $17(18)$ & .73 & $.63, .84$ & .053 & .32 & .002 \\
\hline Any domestic incident $^{\mathrm{a}}$ & $37(40)$ & .71 & $.61, .82$ & .055 & .36 & $<.001$ \\
\hline \multirow{2}{*}{$\begin{array}{l}\text { Substance in any post-index } \\
\text { offense }\end{array}$} & 36 (39) & .68 & $.57, .79$ & .057 & .30 & .003 \\
\hline & Mean (SD) & & & & & \\
\hline Number of offenses & $5.73(9.30)$ & & & & .46 & $<.001$ \\
\hline Number of violent offenses & $1.11(1.94)$ & & & & .29 & .005 \\
\hline $\begin{array}{l}\text { Number of violent or contact } \\
\text { sex offenses }\end{array}$ & $1.26(2.38)$ & & & & .32 & .002 \\
\hline Number of nonviolent offenses & $1.95(3.20)$ & & & & .39 & $<.001$ \\
\hline
\end{tabular}

Note: AUC = Area Under the Curve. ${ }^{a}$ Any recidivism relating to an intimate partner offense, including stalking, harassment, violence and release failures. ${ }^{\mathrm{b}}$ Prorated ODARA score AUC $=.66(S E=.062), 95 \% \mathrm{CI}=[541, .785]$. 


\section{Cumulative Percent}

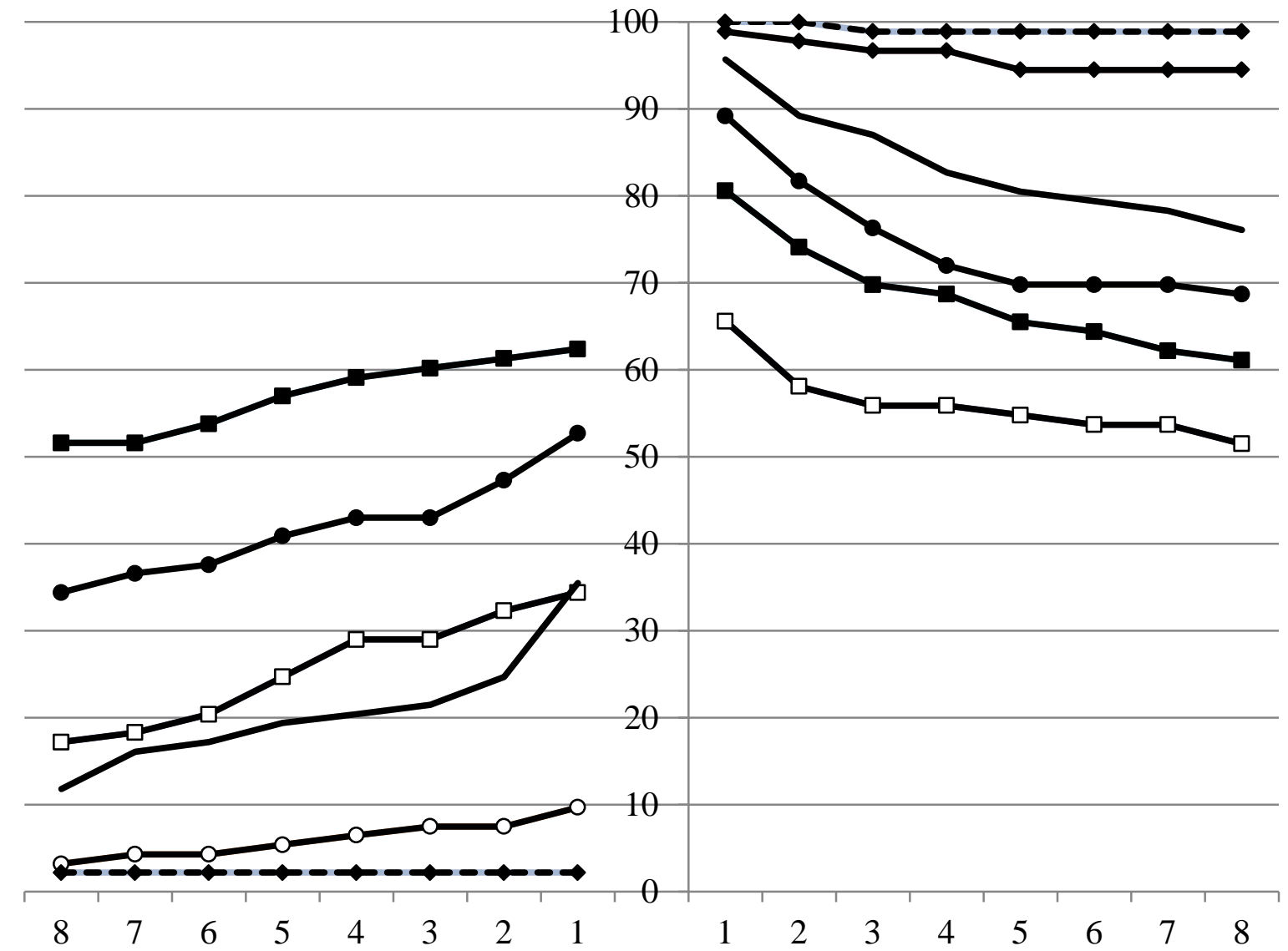
a. Years Pre-Index (Hazard)
Index Assault Date
b. Years Post-Index (Survival)

Figure 1. Cumulative Percent of Offenders with an Intimate Partner Violence Offense at an Index Time Point (“Index Assault”) Who Commit Different Offense Types a. Pre-Index Assault (Hazard Curve) and b. Post-Index Assault (Survival). Offense types shown by non-smoothed curves: solid squares—nonviolent, solid circles_any violence, open squares—failure on conditional release, solid line —IPV, open circles—stalking (only observed pre-index), diamonds solid line—_contact sexual (only observed post-index), diamonds dashed linenoncontact sexual. Rising hazard curves show the cumulative proportion of cases entering each offense-type career, and falling survival curves show the cumulative proportion of offenders not yet recidivating with that offense type. Prior violent offenses include but are not limited to IPV 
charges. The increase in violent offenses in the year prior to the index assault date is, though, attributable to an increase in IPV offenses, possibly a result of victims reporting a cluster of recent assaults when reporting the index assault. 